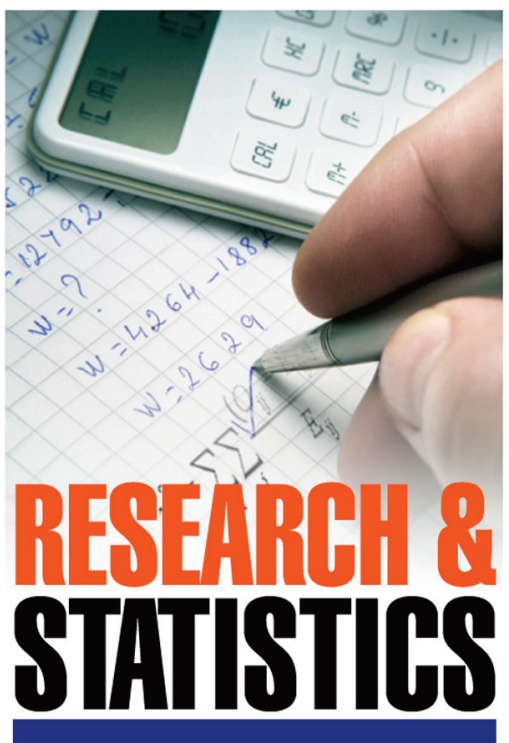

Author Disclosure

Drs Crewe and Rowe have disclosed no financial relationships relevant to this article. This commentary does not contain a discussion of an unapproved/investigative use of a commercial product/device.

\section{Likelihood Ratio in Diagnosis}

Stephanie Crewe, MD, ${ }^{*}$ Peter C. Rowe, $\mathrm{MD}^{+}$

Case Study

You are evaluating an 18-year-old girl who has dysuria. Using your understanding of the epidemiology of urinary tract infections (UTIs) in adolescents, your knowledge of the signs and symptoms of UTI, and your clinical judgment of how ill she appears, you arrive at a pretest estimation that she has a $40 \%$ probability of having a UTI. You wonder how much the probability of UTI will change if the urinalysis shows white blood cells (WBCs) in the urine.

\section{Evaluating Diagnostic Test Results}

Diagnostic tests are used in practice to enhance clinical decision making and especially to revise probabilities in individual patients. (1) A diagnostic test is often ordered to modify the practitioner's initial estimation of

*Assistant Professor, Division of Adolescent Medicine, VCU Health Systems, Richmond, VA ${ }^{+}$Professor of Pediatrics, Department of Pediatrics, Division of General and Adolescent Medicine, Johns Hopkins University School of Medicine, Baltimore, MD. disease probability (pretest probability) and generates the probability of disease after the test (posttest probability). Practitioners and patients probability because this knowledge can help in deciding whether a diagnosis can be confirmed and treatment initiated, if a diagnosis can be ruled out and treatment withheld, or if further tests are needed. (2)

An effective and practical (if underused) approach to evaluating test results is the likelihood ratio (LR). LRs provide a reasonable estimate of the degree to which a test result will change the probability of an individual patient having a disease. (2) They provide a summary of how many times more (or less) likely patients who actually have the disease are to demonstrate a particular result compared with patients who do not have disease. Simply stated, an LR is the percentage of ill people who have a given test result divided by the percentage of well individuals who have the same result. (3) LRs can be calculated from a $2 \times 2$ table, as shown in Figure 1. Alare most interested in the posttest

\begin{tabular}{|c|c|c|}
\hline \multirow[b]{2}{*}{$\begin{array}{l}\text { Positive Test } \\
\text { Result }\end{array}$} & \multicolumn{2}{|c|}{ Disease } \\
\hline & $\begin{array}{c}\text { Present } \\
\mathrm{a}\end{array}$ & $\begin{array}{c}\text { Absent } \\
\mathrm{b}\end{array}$ \\
\hline \multirow[t]{2}{*}{$\begin{array}{c}\text { Negative Test } \\
\text { Result }\end{array}$} & c & d \\
\hline & $a+c$ & $b+d$ \\
\hline \multicolumn{3}{|c|}{$\begin{array}{l}\text { LR for a positive test }=[\mathrm{a} /(\mathrm{a}+\mathrm{c}) \div \mathrm{b} /(\mathrm{b}+\mathrm{d})] \text { or sensitivity } \div(1 \text {-specificity } \\
\text { LR for a negative test }=[\mathrm{c} /(\mathrm{a}+\mathrm{c}) \div \mathrm{d} /(\mathrm{b}+\mathrm{d})] \text { or }(1 \text {-sensitivity }) \div \text { specificity }\end{array}$} \\
\hline
\end{tabular}

Figure 1. General calculation of likelihood ratios. 


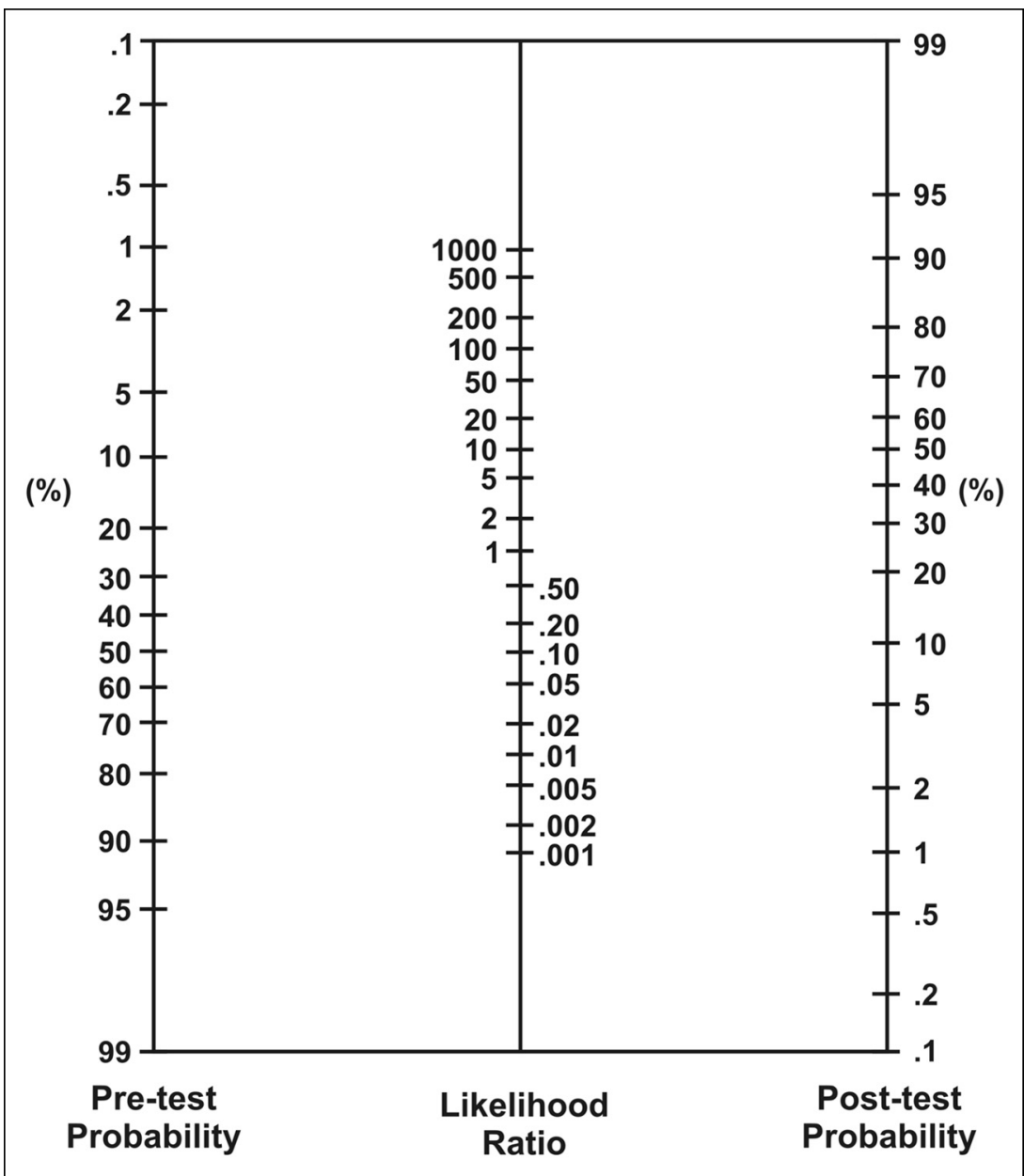

Figure 2. Nomogram for pre- and posttest probabilities and likelihood ratios. A line can be drawn from the pretest probability estimate on the left side of the figure through the likelihood ratio to identify the posttest probability of disease. Modified from Jaeschke et al. (5) Used with permission of the Massachusetts Medical Society.

Urinary Tract Infection (culture-proven)

Urine Test

White blood cells $\geq 50$

White blood cells $<50$

\begin{tabular}{|c|c|}
\hline Present & Absent \\
\hline 17 & 4 \\
\hline 7 & 32 \\
\hline 24 & 36 \\
\hline
\end{tabular}

Sensitivity $=\mathrm{a} /(\mathrm{a}+\mathrm{c})=17 / 24=0.708$

Specificity $=\mathrm{d} /(\mathrm{b}+\mathrm{d})=32 / 36=0.889$

LR for a positive test $=[\mathrm{a} /(\mathrm{a}+\mathrm{c}) \div \mathrm{b} /(\mathrm{b}+\mathrm{d})]=17 / 24 \div 4 / 36 \approx 6.4$

LR for a negative test $=[\mathrm{c} /(\mathrm{a}+\mathrm{c}) \div \mathrm{d} /(\mathrm{b}+\mathrm{d})]=7 / 24 \div 32 / 36 \approx 0.33$

Figure 3. Calculation of likelihood ratios for urine microscopy. (6) though posttest probabilities can becalculated, the Fagan nomogram (Fig. 2) is a convenient tool that shows how a test that has a known LR can change the pretest probability. (4)

An LR greater than 1 increases the probability that the target disorder is present, and the higher the LR, the greater this increase. Conversely, an LR less than 1 decreases the probability of the target disorder, and the smaller the LR, the greater the decrease in probability. (5) LRs of different sizes have different clinical implications; the further the LR is from 1.0 , the greater its effect on the probability of disease. (3) For example, an LR greater than 10 or less than 0.1 generates large and often conclusive changes from pretest to posttest probability. On the other hand, LRs of 1 to 2 and 0.5 to 1 alter probability to a small (and rarely important) degree. (4)

LRs offer several advantages in the clinical setting compared with other statistical methods of assessing the properties of diagnostic tests. (1) They are useful across an array of disease frequencies and allow the test results to be applied to a specific patient. Not only can LRs be used for dichotomous results, but they can be applied to tests involving multiple levels of results. This property enables clinicians to interpret and use a full range of diagnostic test outcomes. (3)

\section{Case Continuation}

$A$ recent study demonstrated the utility of urgent urine microscopy for improving the diagnosis of UTI, particularly when there are more than 50 WBCs per high-power field ( $h p f)$. (6) Using the study results (Figure 3), the calculated sensitivity of more than 50 WBCs for diagnosing UTI is 0.708 and specificity is 0.889 . The LR 


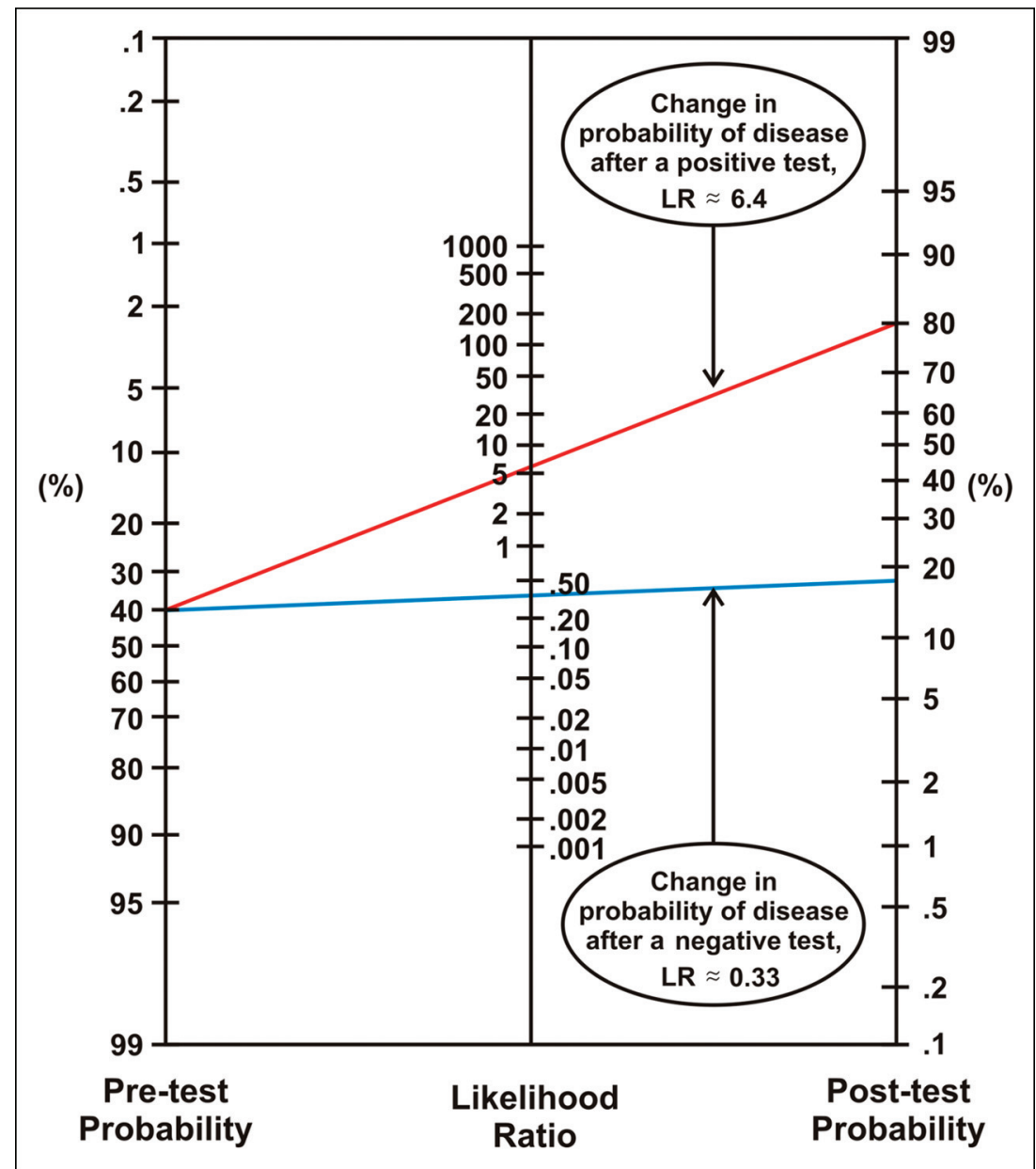

Figure 4. Effects of a likelihood ratio of a positive and a negative test for urinary white blood cells on the posttest probability of your patient having a urinary tract infection. The pretest probability is $40 \%$. of a positive test is approximately 6.4; the LR of a negative test is approximately 0.33. Using the Fagan nomogram and a pretest probability of $40 \%$, note how much a positive or negative result on this test changes the posttest probability (Fig. 4). The LR for a positive test increases the posttest probability of UTI to approximately $80 \%$, while a negative test reduces the posttest probability to below 20\%.

Your patient has a positive urine microscopy showing more than $50 \mathrm{WBCs} / \mathrm{hpf}$. Knowing that the posttest probability is approximately $80 \%$, you feel comfortable treating with antibiotics rather than simply waiting until the culture results return. (1)

\section{References}

1. Schechter M, Sheps S. Diagnostic testing revisited: pathways through uncertainty. Can Med Assoc J. 1985;132:755-760

2. Akobeng A. Understanding diagnostic tests 2: likelihood ratios, pre- and post-test probabilities and their use in clinical practice. Acta Paediatr. 2006;96:487-491

3. Grimes D, Schultz K. Refining clinical diagnosis with likelihood ratios. Lancet. 2005;365:1500-1505

4. Fagan T. Nomogram for Bayes theorem [letter]. N Engl J Med. 1975;293:257

5. Jaeschke R, Guyatt G, Sackett D, for the Evidence-Based Working Group. Users' guides to the medical literature. III: How to use an article about a diagnostic test, B: What are the results and will they help me in caring for my patients? JAMA. 1994;271:703-707 6. Leman P. Validity of urinalysis and microscopy for detecting urinary tract infection in the emergency department. Eur J Emerg Med. 2002;9:141-147 